Military Technical College

Kobry El-Kobbah, Cairo, Egypt.

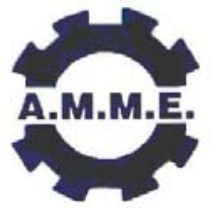

$13^{\text {th }}$ International Conference on Applied Mechanics and Mechanical Engineering.

\title{
AN INVESTIGATION OF THE EFFECT OF WORKING GAS TYPE ON MORPHOLOGICAL FEATURES OF THE DEPOSITED LAYERS ON A STEEL ALLOY PRODUCED BY IMPULSE PLASMA DEPOSITION TECHNIQUE
}

RASHAD* M.M., HASSAN ${ }^{*}$ M.F.A, HASSAN* K.A.A. and OSMAN M.M. ${ }^{*}$

\begin{abstract}
This paper is concerned with the nature and morphology of deposited Carbon - Alumina coatings produced under various discharging conditions of the Impulse Plasma Deposition (IPD) process. The deposition of the coating material was carried out on a non-heated steel substrate by means of plasma pulses generated from a coaxial plasma gun. The pulsed plasma mainly consists of two kinds of ions: working gas ions and inner electrode ions. Coatings were produced by a number of plasma pulses (50 200) from $15.42 \mu \mathrm{F}$ capacitor bank at $13.5 \mathrm{kV}$ discharging voltage. The microstructure of the deposited films was observed using scanning electron microscope (SEM). Structural features were greatly affected by the type of the working gas which controls the ionization potential. Using the Acetylene $\left(\mathrm{C}_{2} \mathrm{H}_{2}\right)$ only as a working gas produces a layer of graphite and coarse alumina particles $\left(\mathrm{AL}_{2} \mathrm{O}_{3}\right)$ with non uniform distribution. Mixing the used gas with a molecular gas (either $\mathrm{N}_{2}$ or $\mathrm{H}_{2}$ ) enhances the ionization and gives more uniform distribution of finer alumina particles.
\end{abstract}

\section{KEY WORDS}

Carbon - Alumina coatings, IPD process, SEM, Plasma Coaxial Gun.

\footnotetext{
Egyptian Armed Forces
} 


\section{INTRODUCTION}

Industrial evolution and progressively increasing demands for new materials, having superior properties to be used in different applications, set a huge responsibility on the scientists as well as researchers. A great effort is done to achieve these requirements by adopting different trends. One of these trends is to compose a combination of different materials having widespread properties (composite material), whereas other to achieve properties variation through the thickness of the material (multi grade functional material). This lateral technique requires well-controlled treatment conditions to reach the required properties profile which is difficult. In many applications, only the surface layer is required to be with superior properties rather than the whole bulk material. One simple way to enhance the material surface properties is to deposit a thin film layer on the periphery of the final product. This deposited layer increases the material surface hardness, its corrosion resistance as well as its wear resistance. Also, it may act as a self-lubricant, antistatic and thermal barrier coating [1]. Coatings produced by impulse plasma deposition (IPD) method utilize the plasma generated and accelerated by the Lorentz force in a coaxial plasma gun [2]. This technique has the advantages of having good adhesion between the deposited film and the substrate, high deposition rate, efficient energy conversion, room temperature operation and low structural asset [3]. Different deposited films with different compositions and physical as well as mechanical properties could be obtained by changing the electrodes material, working gases and operation parameters [4]. Accomplishment of carbon coatings using the stated technique have a wide variety of industrial applications due to their high hardness, excellent corrosion resistance, wide range of optical transparency and electrical properties [5-9]. Carbon films in the form of Diamond-like Carbon (DLC) were deposited by using high-density plasma by different techniques [5].

The aim of the present research work is to study and focus on the influences of the working gas type on the structural features of the deposited Carbon - Alumina layers. These layers are produced on a steel substrate at room temperature utilizing an IPD technique. The plasma coaxial gun used for that purpose is a device capable of transforming electrical energy into kinetic energy in the form of direct plasma jet [10]. Bursts of plasma containing ions, atoms and electrons is produced and accelerated into vacuum chamber at a velocity of about $10^{4} \mathrm{~m} / \mathrm{s}$ to bombard the target $[5,11]$. These species of charged particles are deposited on the substrate surface and implanted into the bulk. Acetylene gas $\left(\mathrm{C}_{2} \mathrm{H}_{2}\right)$ is used as a source of carbon atoms. While the inner electrode is the source of the Aluminum present in the deposited Alumina phase. In addition to the use of $\mathrm{C}_{2} \mathrm{H}_{2}$ as a working gas, further gas mixtures such as $\left(\mathrm{C}_{2} \mathrm{H}_{2} / \mathrm{N}_{2}\right)$ and $\left(\mathrm{C}_{2} \mathrm{H}_{2} / \mathrm{H}_{2}\right)$ with different ratios are used to reveal the stated aim of this research work.

\section{EXPERIMENTAL PROCEDURE}

Steel substrates with the chemical composition shown in Table. 1 are prepared in 20 $\mathrm{mm} \times 20 \mathrm{~mm} \times 10 \mathrm{~mm}$ for deposition process. Before bombardment, the samples are prepared by grinding using different grades of emery papers (180-800), then mechanically polished with $0.25 \mu \mathrm{m}$ diamond suspension on a cloth pad, and finally washed by methanol. A schematic diagram of the plasma coaxial gun system used for deposition of Carbon-Alumina films by the IPD method is shown in Fig.1, where as the construction of the plasma coaxial gun head is shown in Fig.2. Mainly the plasma gun 
head consists of two coaxial hollow cylindrical electrodes welded to the vacuum chamber. The inner electrode is $11 \mathrm{~cm}$ in length and $2 \mathrm{~cm}$ in diameter while the outer electrode is $10.5 \mathrm{~cm}$ in length and $4 \mathrm{~cm}$ in diameter. The two electrodes are isolated from each other by a Teflon disc. The discharge takes place between the inner and outer electrode. A clamping mechanism is designed to hold the iron substrate during deposition of the ejected particles. While the coaxial tube is fixed in vertical position, the plasma sheath moves upwards [12]. The dimensions of the vacuum chamber are choosen to be $13.5 \mathrm{~cm}$ in length and $8.6 \mathrm{~cm}$ in diameter to secure the suitable vacuum level can be attained with the used vacuum pump. A metallic flange (ring flange) is attached to the end of the vacuum chamber using fixation bolts with sealing ring in between to prevent air/gas leakage into the vacuum chamber.

Specimens are treated with the designed plasma gun system with $13.5 \mathrm{kV}$ discharging voltage, $100 \mathrm{mTorr}$ chamber gas pressure and $1 \mathrm{~cm}$ substrate distance from the gun muzzle during each regime of experiments. Three groups of prepared specimens are subjected to the produced plasma jet in each regime of experiments with successive 50,100 and 200 plasma pulses. The first regime of experiments is done in $\mathrm{C}_{2} \mathrm{H}_{2}$ atmosphere only as a working gas which is fed to the inlet of the vacuum chamber. While a mixture of $\mathrm{C}_{2} \mathrm{H}_{2} / \mathrm{N}_{2}$ with a ratio of $1 / 2$ is used in the second regime. In the third regime of experiments, mixtures of $\mathrm{C}_{2} \mathrm{H}_{2} / \mathrm{H}_{2}$ with a ratio of $1 / 2$ and $1 / 5$ respectively are used. The energy driving the plasma processes is supplied from a $15.42 \mu \mathrm{F}$ capacitor bank, via a spark gap switch, which was charged prior to each plasma pulse. A rotary pump of Alcatel type model 2010 is connected to the outlet of the vacuum chamber. Its ultimate pressure reaches (1.52 mTorr) but the working gas pressure is about 100 mTorr. The pressure of the working gas is adjusted using a pressure gauge type VRC (vacuum research corporation of USA). A needle valve is used to regulate and control the flow of the working gases; also it secures the whole system from explosion due to escaping plasma spark to the gas tubes. The potential difference between the two electrodes is measured by a capacitive potential divider. Rogowisky coil is designed to be used in measuring the discharging current. The particle size is carried out using image analysis software SIGMA SCAN PRO version 5 which is a complete image analysis solution that helps transforming image into scientific data and valuable conclusions. This software is able to measure, store data, classify and draw the histogram of the investigated particles.

\section{RESULTS AND DISCUSSION}

\section{Microstructure of the Deposited Thin Film (DTF) when using $\mathrm{C}_{2} \mathrm{H}_{2}$ as a working gas}

The microstructure of the first group of specimens that were exposed to 50 successive plasma pulses with the previously stated conditions is shown in Fig.3. In this figure, one can notice discrete islands of bright phases (Alumina) on the substrate surface surrounded by a wide dark area of graphite. Increasing the bombardment number to twice its value ( 100 pulses) more second phase particles with coarser sizes are deposited on the substrate surface of the second group of specimens as shown in Fig.4. The Sigma Scanpro software gives statistical measurements show that the size of these islands has a wide range from $2.5 \mu \mathrm{m}$ to $45 \mu \mathrm{m}$. Exposing the third group to 200 successive pulses coarsen the size of the deposited particles and causes more clusters to form as shown in Fig.5. 


\section{Microstructure of the DTF when using a mixture of $\mathrm{C}_{2} \mathrm{H}_{2} / \mathrm{N}_{2}$ with a ratio of $1 / 2$ as a working gas}

Figure 6.a represents the microstructure of these specimens exposed to 50 successive plasma pulses where the deposited particles show a nonuniform distribution since they cluster with each other and concentrate in very narrow zones leaving around vast areas almost free from the deposited particles. Fig.6.b shows the morphology of these deposited particles with higher magnifications where the coarse particles have a flowery shape. The particles size ranges from $0.5 \mu \mathrm{m}$ to $15.5 \mu \mathrm{m}$ which is relatively finer than those of deposited in the presence of $\mathrm{C}_{2} \mathrm{H}_{2}$ only as a working gas.

Increasing the number of plasma pulses to 100 and 200 pulses, respectively changes the distribution as well as the morphology of the deposited particles. Fig.7a shows more deposition and better distribution that will have a sensible impact on the mechanical properties of the deposited layer. Higher magnification, Fig.7b reveals the shape changes accompanied the number of pulses increasing. In this figure, the particles are almost perfect spheres and uniformly distributed. In this figure two size ranges are clearly observed, coarse particles in the range of (10.5-30) $\mu \mathrm{m}$ and finer particles in the range of $(0.7-10) \mu \mathrm{m}$.

\section{Microstructure of the DTF when using a mixture of $\mathrm{C}_{2} \mathrm{H}_{2} / \mathrm{H}_{2}$ with a ratio of $1 / 2$ as a working gas}

Despite the fact that mixing the $\mathrm{C}_{2} \mathrm{H}_{2}$ with $\mathrm{N}_{2}$ gives enhanced deposition and more uniform deposited layer than that layers formed when using $\mathrm{C}_{2} \mathrm{H}_{2}$ only, there was a motivation to mix the $\mathrm{C}_{2} \mathrm{H}_{2}$ with a lighter gas as $\mathrm{H}_{2}$. Many researchers $[5,13]$ used this candidate as a working gas because of its superior effect on both the deposition kinetics (enhances the ionization and accelerates the deposition process [14]) and the morphology of the created particles. Fig.8 shows the microstructures of these specimens were exposed to 50 successive plasma pulses. In this microstructure, the particles still have their flowery morphology but a high areal density is observed. Increasing the number of pulses with the same working conditions affects both the particles areal density and their shape. In Fig.9, where the specimens received 100 successive pulses, the number of the deposited particles is remarkably decreased where as their surface morphology is smoother. Increasing the bombardment number to about 200 pulses flattened the deposited particles as a result of the shot pining effect that was carried out during the bombardment as shown in Fig.10.

\section{Microstructure of the DTF when using a mixture of $\mathrm{C}_{2} \mathrm{H}_{2} / \mathrm{H}_{2}$ with a ratio of $1 / 5$ as a working gas}

Using a mixture of $\mathrm{C}_{2} \mathrm{H}_{2}$ and $\mathrm{H}_{2}$ with a mixing ratio $1 / 2$ gives coarse batches of the deposited particles. Raising the magnification to higher values shows no difference than that observed with the lower magnification especially in-between the coarse particles. In the contrary, examining the specimens that were treated in an atmosphere of $\mathrm{C}_{2} \mathrm{H}_{2} / \mathrm{H}_{2}$ with a ratio of $1 / 5$ with high magnifications revealed a uniform distribution of very fine deposited particles in between the normally observed coarse species. Fig.11.a shows the distribution of the coarse particles after receiving 100 successive plasma pulses where as Fig.11.b shows the same structure with higher magnification. Increasing the 
number of bombardment decreases the areal density of the coarse deposited particles, and enhances the formation of uniform fine deposited particles. Figure 12, shows the fine deposited particles distribution where their size seems to be coarser than those obtained with lower bombarding number.

\section{CONCLUSIONS}

Deposition process of Carbon - Alumina layer on a non-heated steel substrate is carried out using a self designed and manufactured plasma coaxial gun system. This deposited layer is intentionally implemented on this substrate to alter its surface properties to be used in different applications with superior requirements. The effect of the working gas type on the microstructure of the deposited layer is studied taking into consideration that any other processing conditions are kept constant. Nature and morphology of the deposited layers are greatly affected by the type of the working gas which controls the ionization potential. Using the acetylene $\left(\mathrm{C}_{2} \mathrm{H}_{2}\right)$ only as a working gas produces a layer of graphite and coarse alumina particles $\left(\mathrm{AL}_{2} \mathrm{O}_{3}\right)$ with non uniform distribution. The particles sizes have a wide range from $2.5 \mu \mathrm{m}$ to $45 \mu \mathrm{m}$ at 100 plasma pulses. Mixing the used gas with a molecular gas (either $\mathrm{N}_{2}$ or $\mathrm{H}_{2}$ ) enhances the ionization process and gives more uniform distribution of finer alumina particles. The size of these fine particles ranged from $(0.7$ to $10 \mu \mathrm{m})$ with 200 plasma pulses in case of utilizing $\mathrm{C}_{2} \mathrm{H}_{2}$ with $\mathrm{N}_{2}$ as a working gas. Using a mixture of $\mathrm{C}_{2} \mathrm{H}_{2}$ and $\mathrm{H}_{2}$ enhances the deposition of fine particles with uniform distribution. As the ratio of $\mathrm{H}_{2}$ gas in the mixture increases the deposited particles are finer and more uniform.

\section{REFERENCES}

[1] Krishna Seshan, "Handbook of Thin-Film Deposition Processes and Techniques", William Andrew Publication, Norwich, New York, U.S.A., (2002).

[2] K.Zdunek, "Spreading of Impulse Plasma Within a Coaxial Accelerator", J.of Surface Coating Technology, Vol. 74-75, pp 949-952, (1995).

[3] Pengxun Yan, Ping Hui, Weiguang Z. and HongsiangTan, "An Investigation of the Pulsed Plasma for Deposition of Thin Film Materials", J.of Surface \& Coating Technology, Vol. 102, pp 175-181, (1998).

[4] Rashad M.M., Masoud M.M., Hassan M.F. and Osman M.M. "Study of the Mechanical and Metallographic Properties of Carbon - Alumina Coated Iron Produced by Impulse Plasma Deposition", $12^{\text {th }}$ International Conference on Applied Mechanics and Mechanical Engineering, M.T.C., Cairo, Egypt, (2006).

[5] Si-ze Yang, Pengxun Yan, Bing Li,Yufeng Ren and Xishen Chen, "Deposition of Diamond-like Films on an Iron Substrate by a Pulsed High-density Plasma Beam at Room Temperature", J. of Materials Chemistry and Physics, Vol. 45, pp 167170, (1996).

[6] S.Witanachchi, A.M.Miyawa and P. Mukherjee, "Highly Ionized Carbon Plasma Generation by Dual-laser Ablation for Diamond-like Carbon Film Growth", J.of Materials Research Society, Vol. 617, pp J.6.1- J.3.6.6, (2000).

[7] Chengming Li, Qi He, Weizhong Tang and Fanxiu Lu, "Carburizing of Steel AISI 1010 by using a Cathode Arc Plasma Process", J.of Surface \& Coating Technology, Vol. 187, pp 1-5, (2004).

[8] Emil Wierzbinski, Monika Mirkowaska, Katarzyna Nowakowska-Langier and 
Krzysztof Zdunek, "Structural Features of Films Obtained by the Impulse Plasma Deposition Method", J.of Surface \& Coating Technology, Vol. 200, pp301-305, (2005).

[9] Monika Mirkowska, Emil Wierzbinski and Krzysztof Zdunek," Growth of Nanopillar $\mathrm{CN}_{\mathrm{X}}$ Layers During Impulse Plasma Deposition" J.of Surface \& Coating Technology, Vol.200, pp 4448-4455, (2005).

[10] M.Abdul Moname, M.Sc. Thesis, "Study of High Density Plasma Spray Parameters Using Plasma Coaxial Accelerator", faculty of science, Benha University, (2000).

[11] Katarzyna Nowakowska-Langier, Krzysztof Zdunek and Michal Kopcewicz, "Phase Structure of The Fe-Ti Layers Produced By The IPD Method", J.of Vacuum, Vol 78, pp 423-426, (2005).

[12] H.A.El-Gamal, M.A.Hassabu, H.A.El-Tayeb and M.Abdul-Moname, "Study of High Density Plasma Spray Parameters Using Plasma Coaxial Accelerator ", J.of Fizika B, Vol. 13, pp 23-32, (2004).

[13] K. Zdunek, "Defects Developed in Ni-Coatings Deposited by the Impulse Plasma on Metal Substrate", J. of Vacuum, Vol. 47, PP 1437-1441, (1996).

[14] A. Grill, "Cold Plasma in Materials Fabrication: from Fundamentals to Applications", IEEE Press, New York, (1994). 
Tabel.1. Chemical composition of the used steel substrates

\begin{tabular}{|c|c|c|c|c|}
\hline Element & $\mathrm{C}$ & $\mathrm{Si}$ & $\mathrm{Mn}$ & $\mathrm{Fe}$ \\
\hline $\mathrm{Wt} \%$ & 0.12 & 0.06 & 2.87 & 96.95 \\
\hline
\end{tabular}

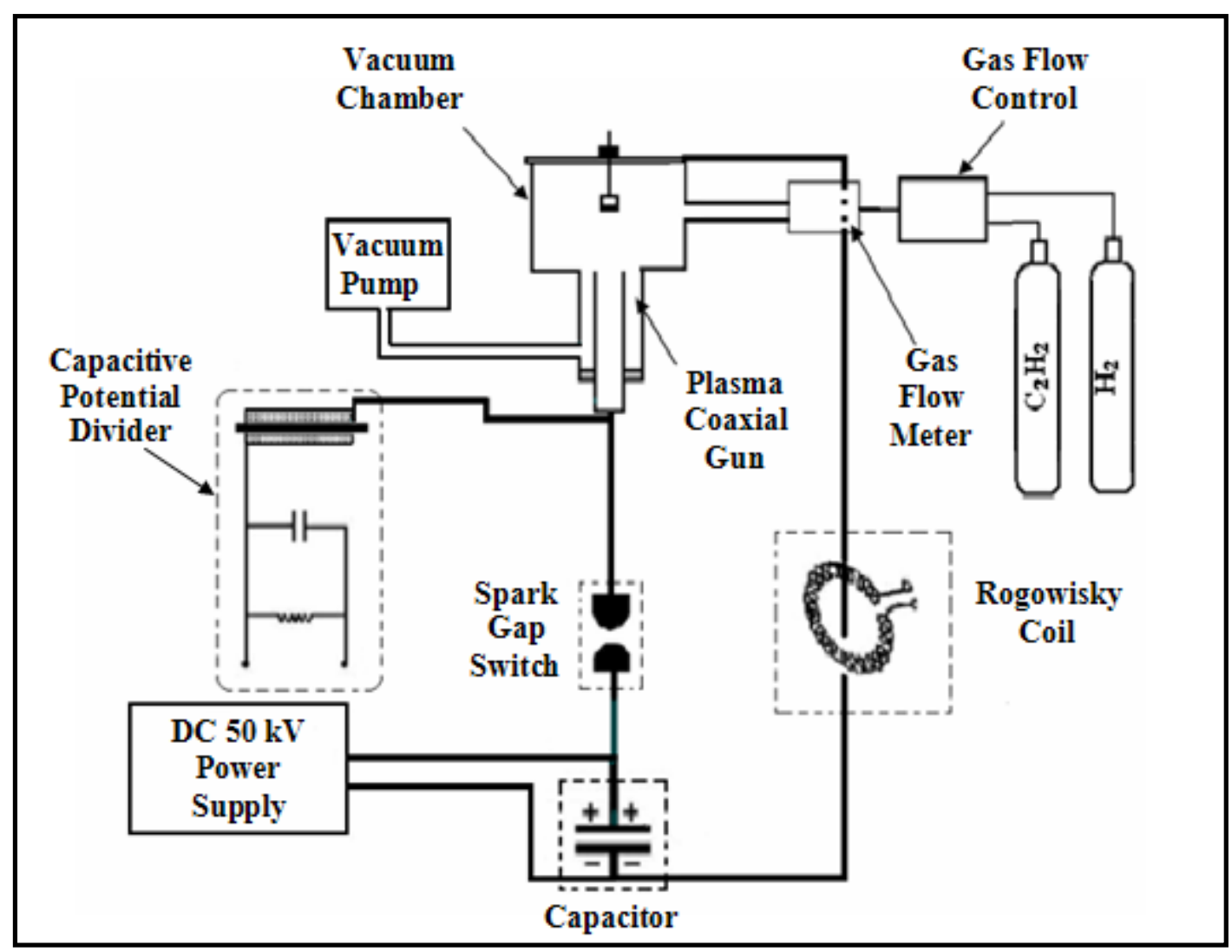

Fig.1. Schematic diagram showing the main parts of the plasma coaxial gun system. 


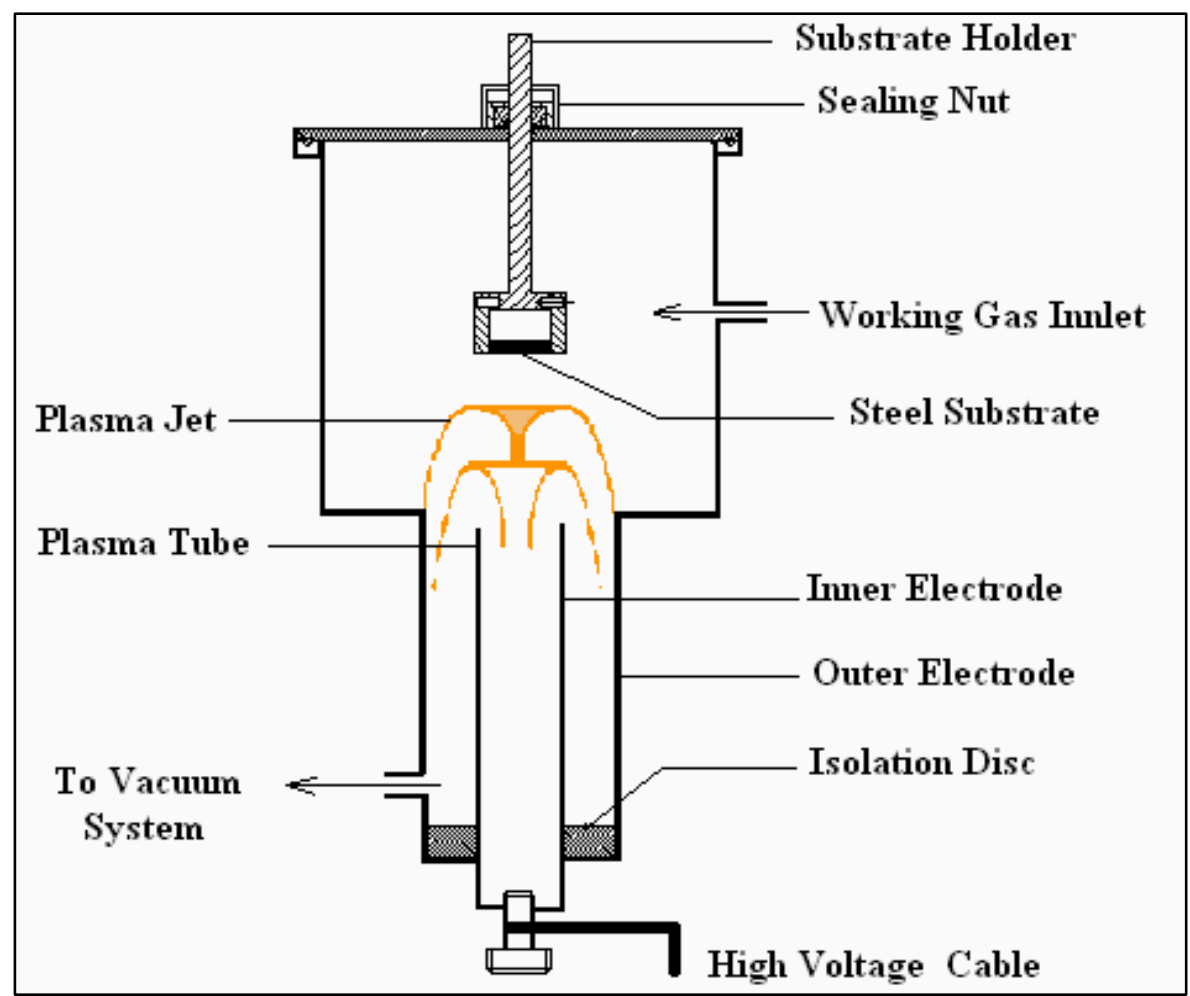

Fig.2. Plasma coaxial gun head

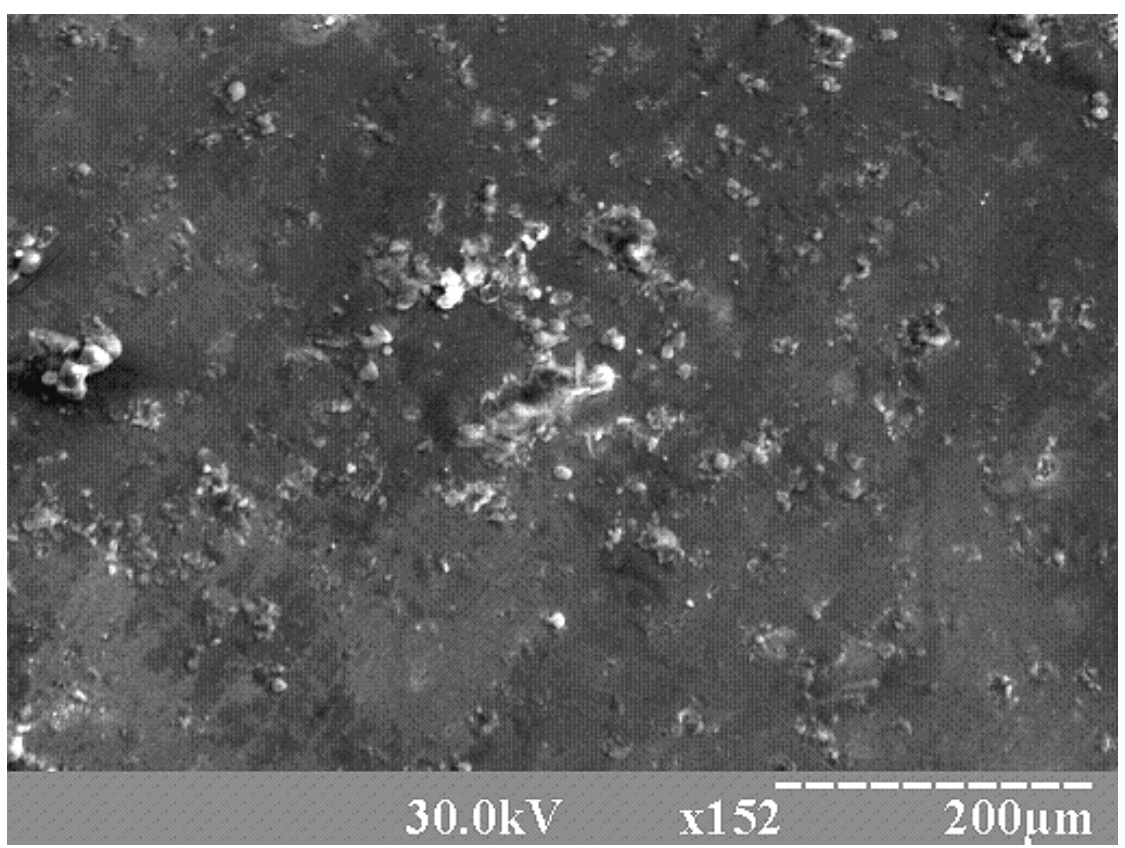

Fig.3. Microstructure of the DTF using $\mathrm{C}_{2} \mathrm{H}_{2}$ as a working gas at $13.5 \mathrm{kV}$ charging voltage, 100 mTorr pressure and 50 plasma pulses. 


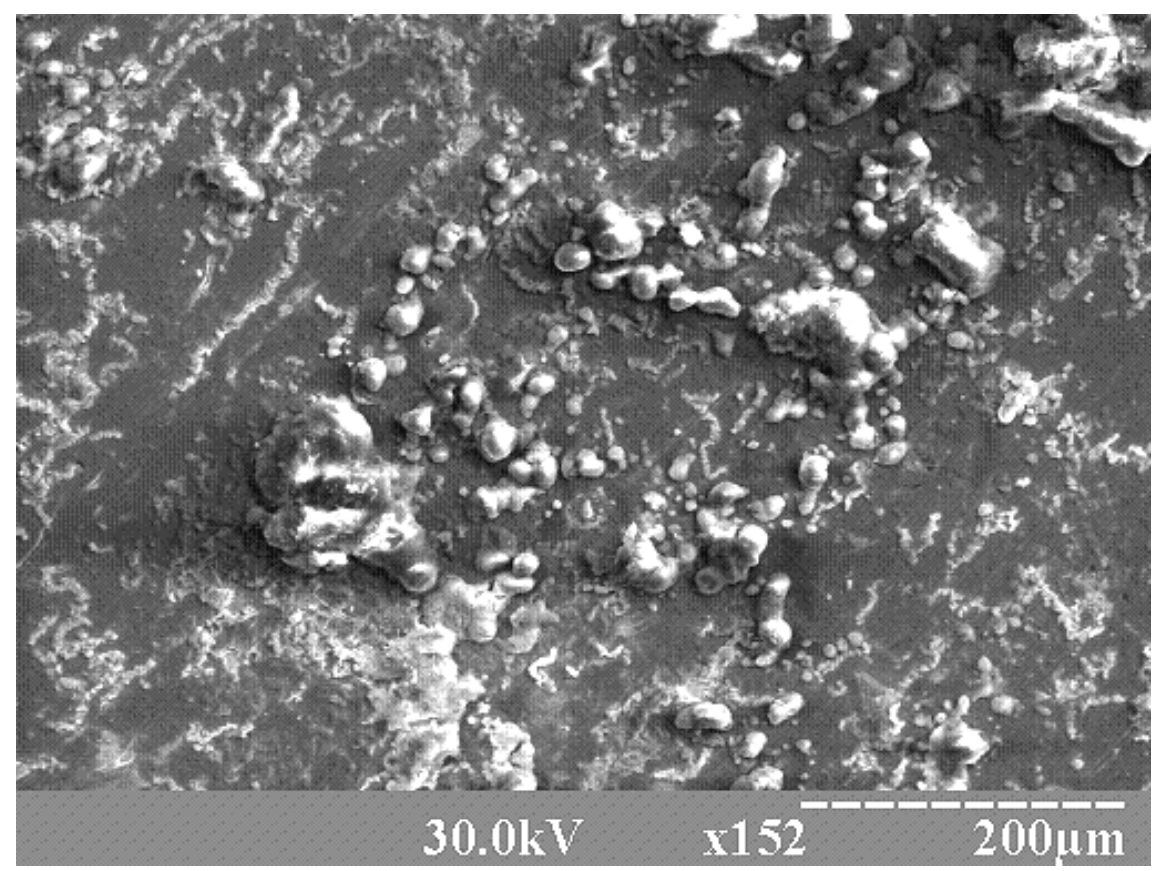

Fig.4. Microstructure of the DTF using $\mathrm{C}_{2} \mathrm{H}_{2}$ as a working gas at $13.5 \mathrm{kV}$ charging voltage, $100 \mathrm{mTorr}$ pressure and 100 plasma pulses.

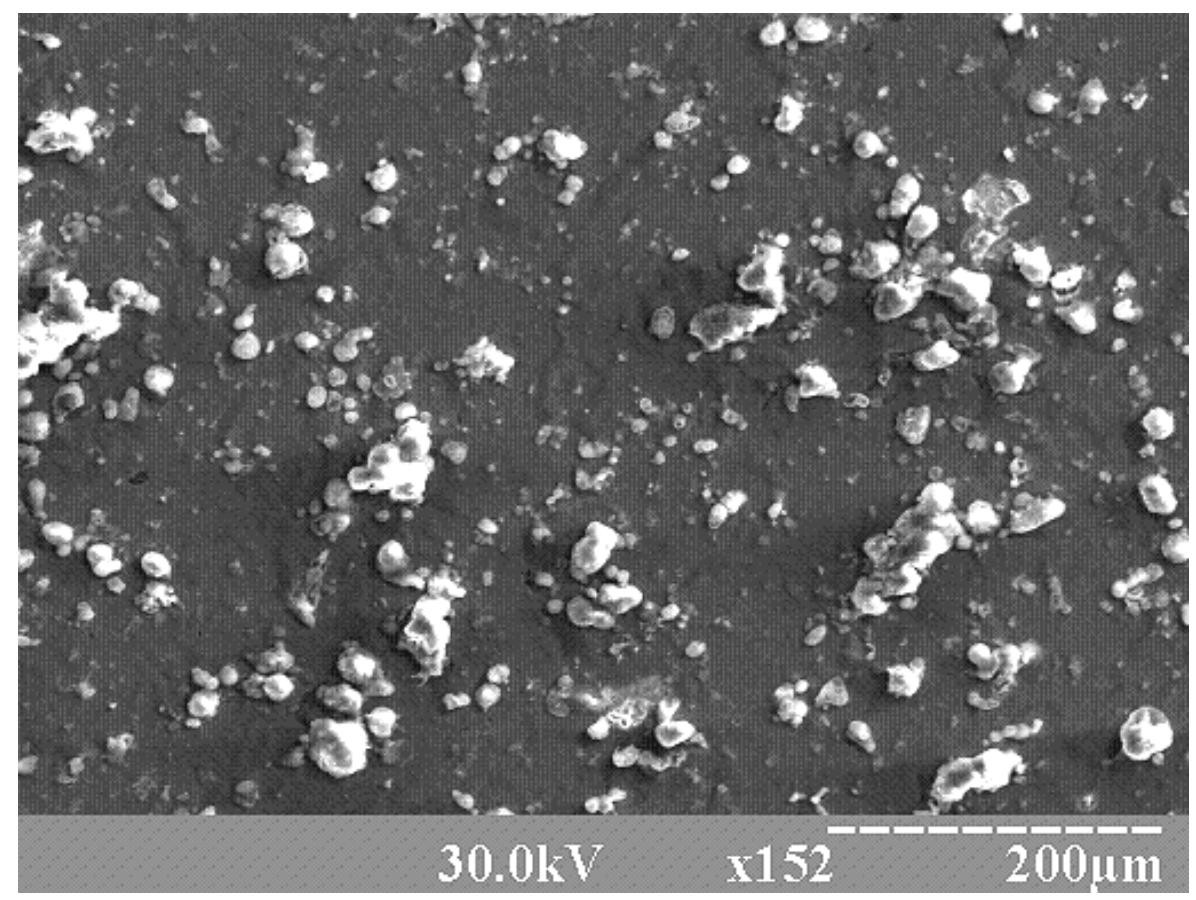

Fig.5. Microstructure of the DTF using $\mathrm{C}_{2} \mathrm{H}_{2}$ as a working gas at $13.5 \mathrm{kV}$ charging voltage, 100 mTorr pressure and 200 plasma pulses. 


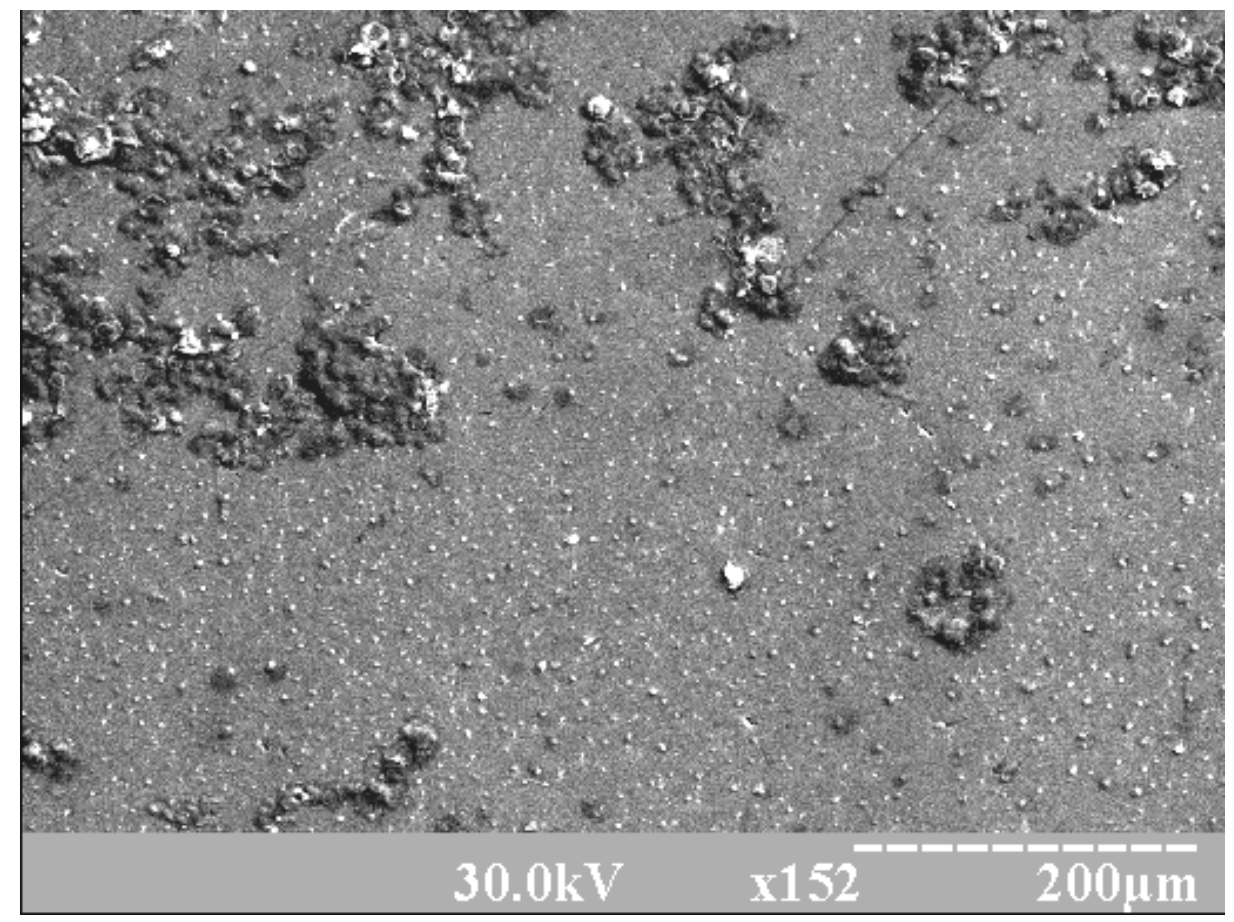

(a)

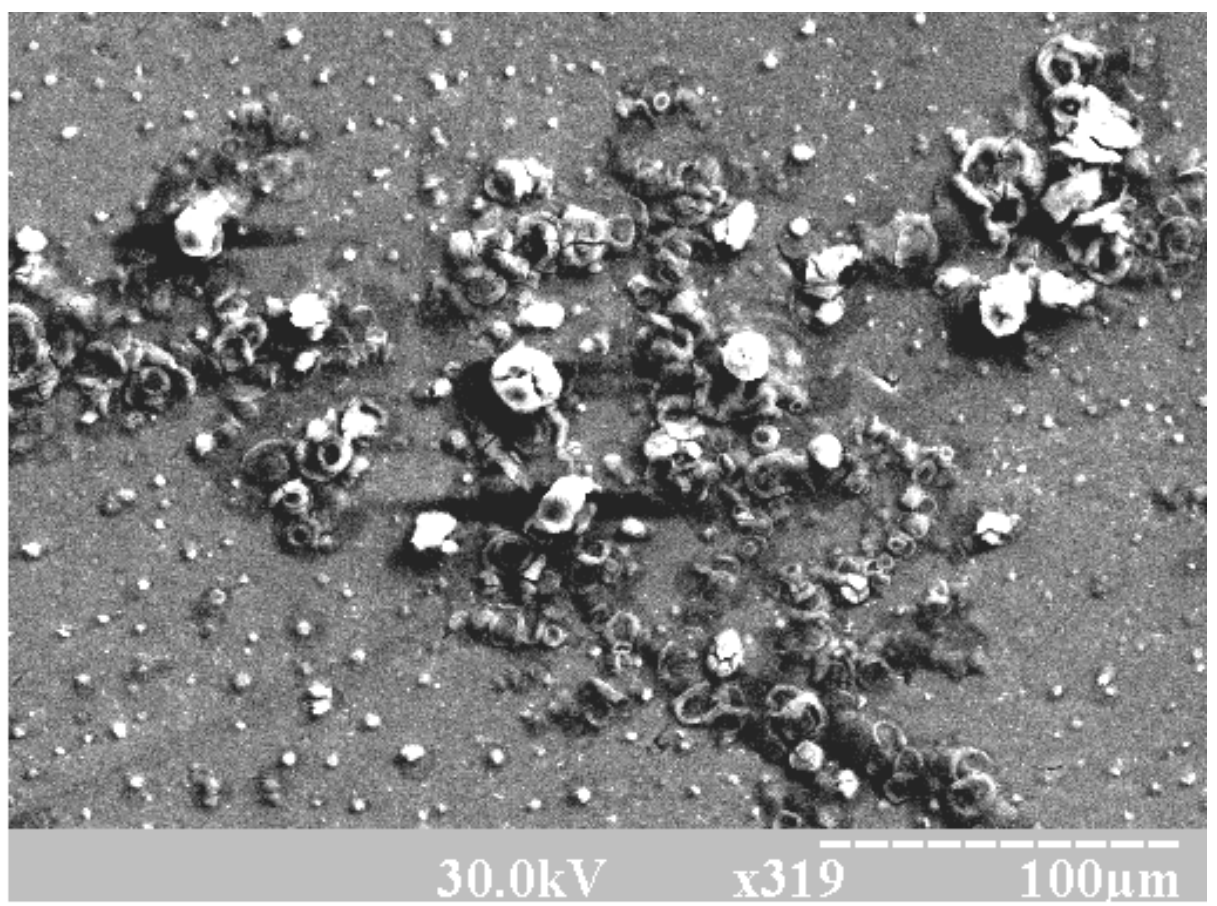

(b)

Fig.6. Microstructure of the DTF using a mixture of $\mathrm{C}_{2} \mathrm{H}_{2} / \mathrm{N}_{2}$ with a ratio of $1 / 2$ as a working gas at $13.5 \mathrm{kV}$ charging voltage, 100 mTorr pressure and 50 plasma pulses.(a) Magnification 152 times. (b) Magnification 319 times. 


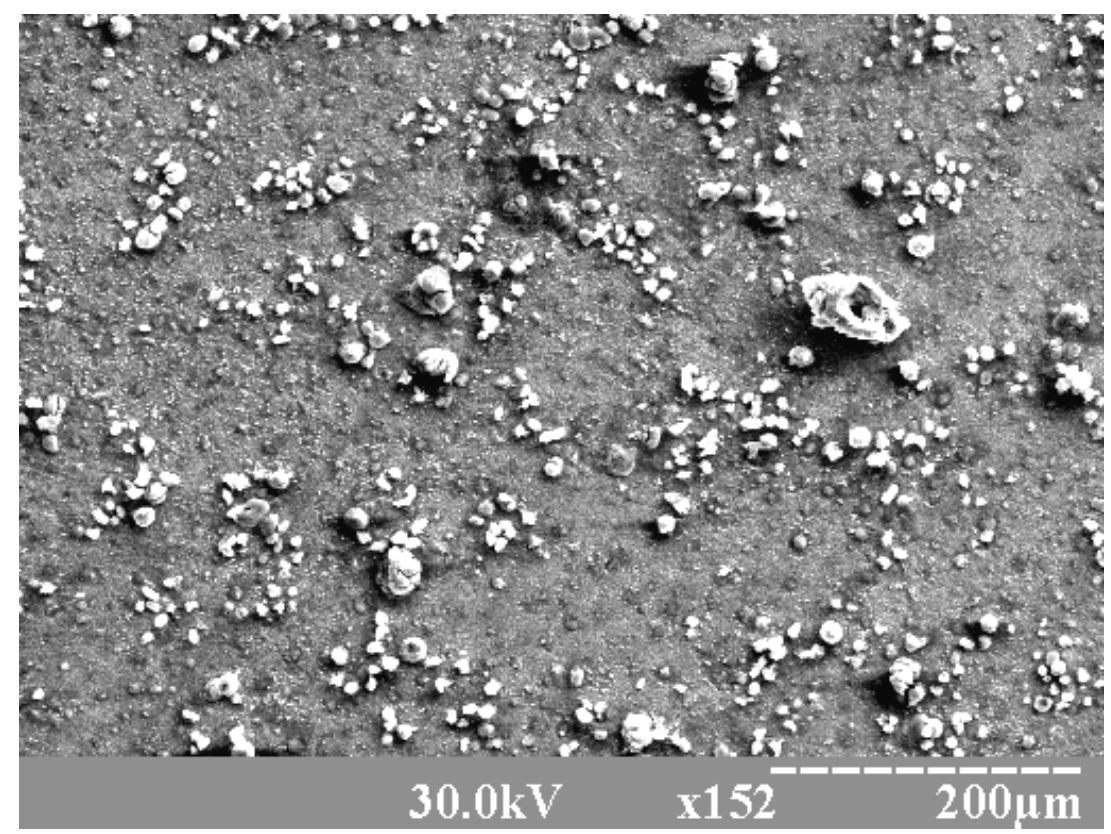

(a)

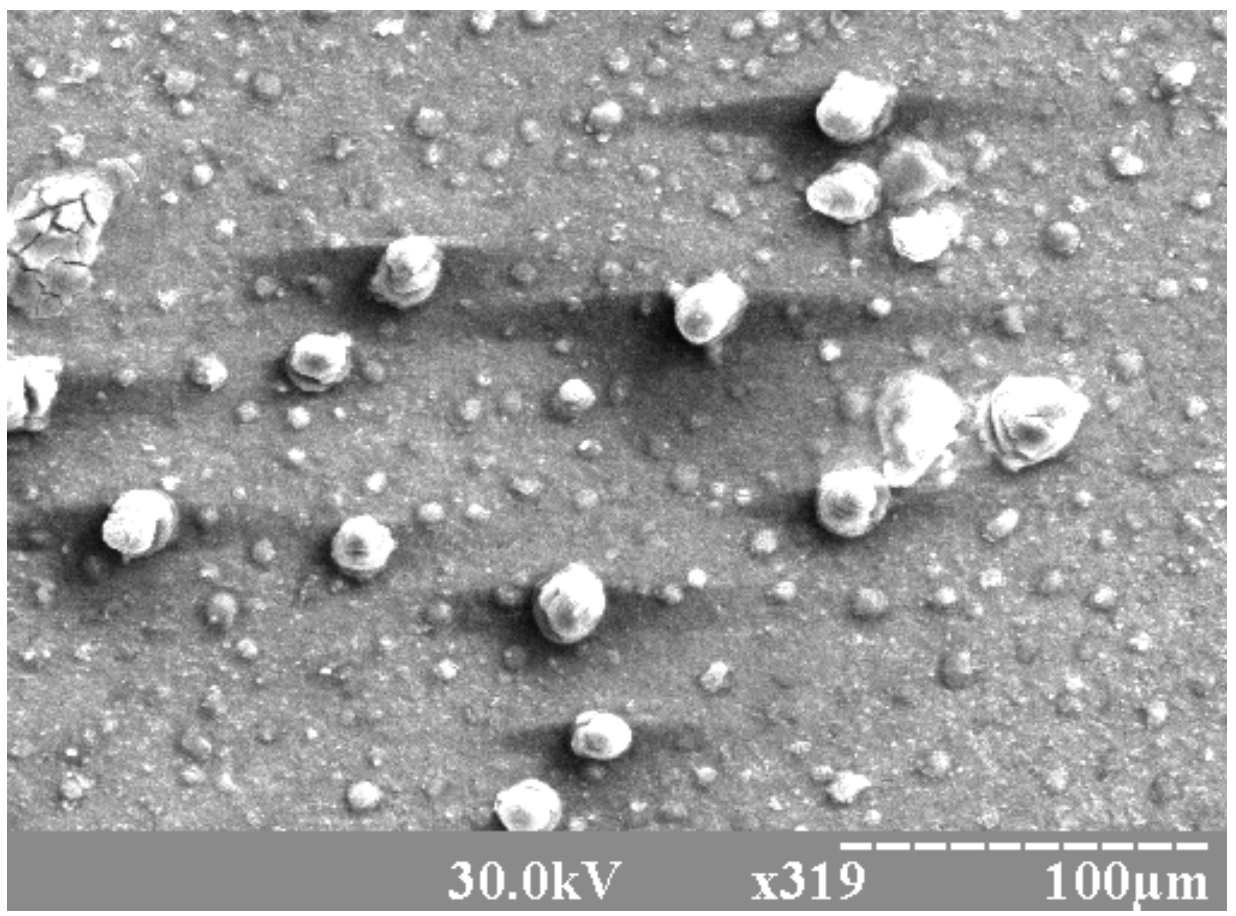

(b)

Fig.7. Microstructure of the DTF using a mixture of $\mathrm{C}_{2} \mathrm{H}_{2} / \mathrm{N}_{2}$ with a ratio of $1 / 2$ as a working gas at $13.5 \mathrm{kV}$ charging voltage, $100 \mathrm{mTorr}$ pressure and 200 plasma pulses.(a) Magnification 152 times. (b) Magnification 319 times. 


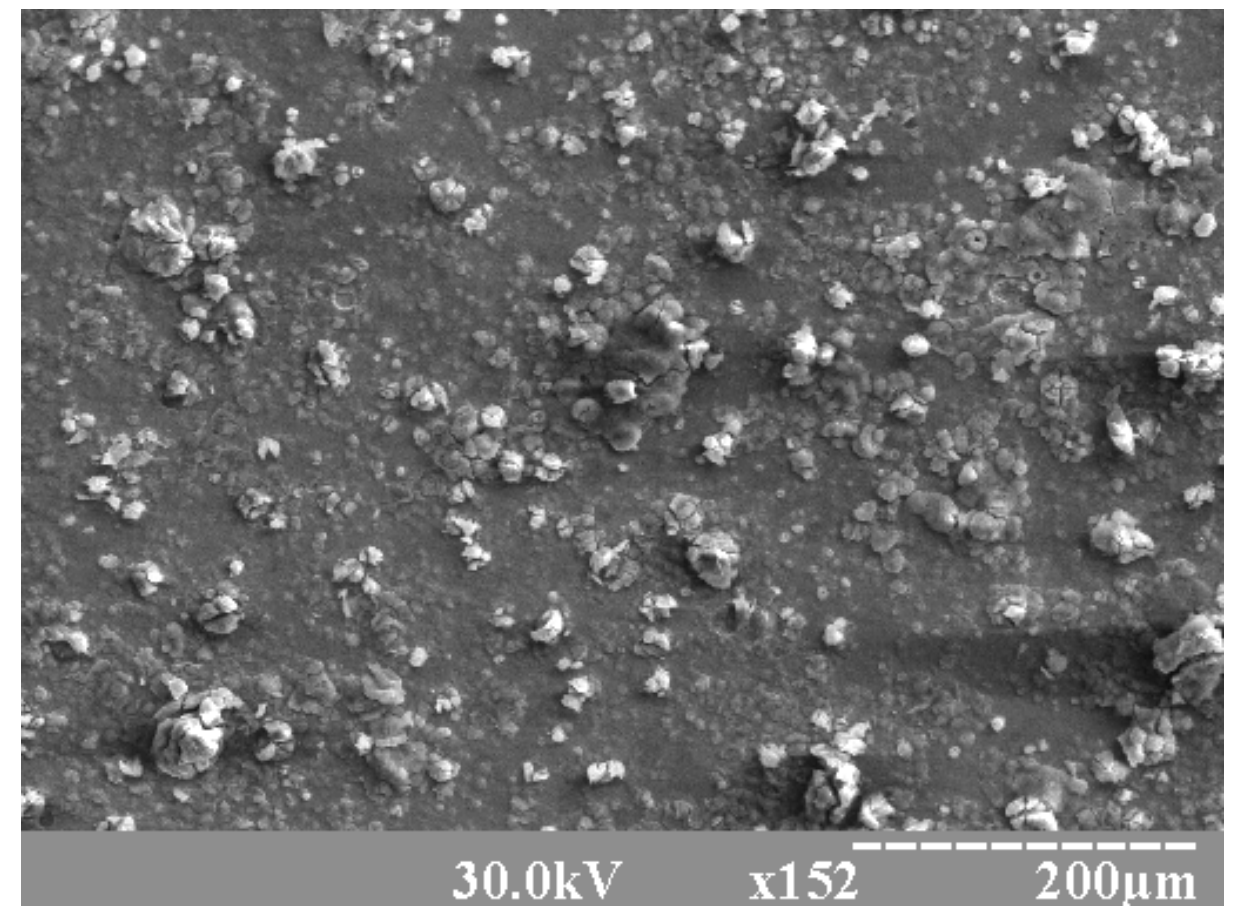

(a)

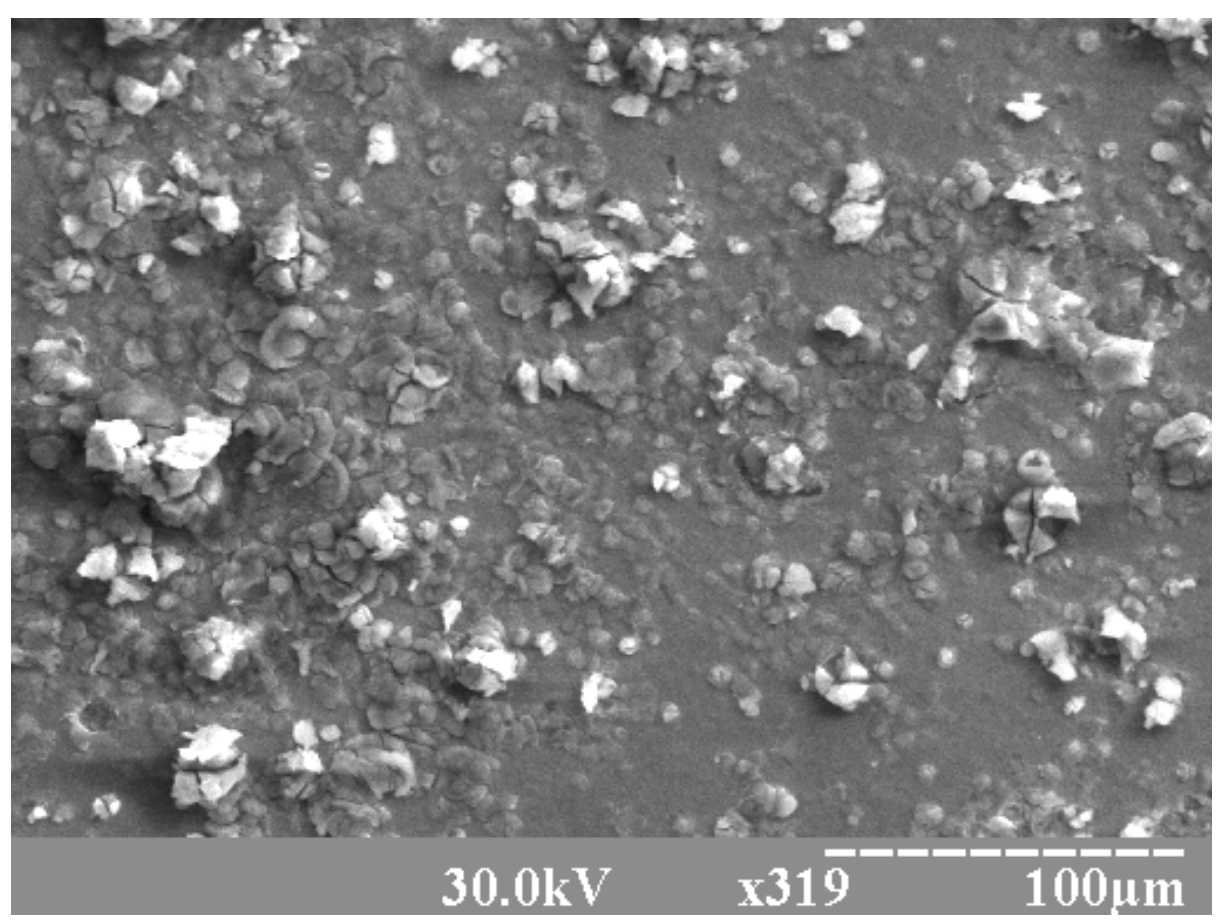

(b)

Fig.8. Microstructure of the DTF using a mixture of $\mathrm{C}_{2} \mathrm{H}_{2} / \mathrm{H}_{2}$ with a ratio of $1 / 2$ at $13.5 \mathrm{kV}$ charging voltage, $100 \mathrm{mTorr}$ pressure and 50 plasma pulses. (a) Magnification 152 times. (b) Magnification 319 times. 


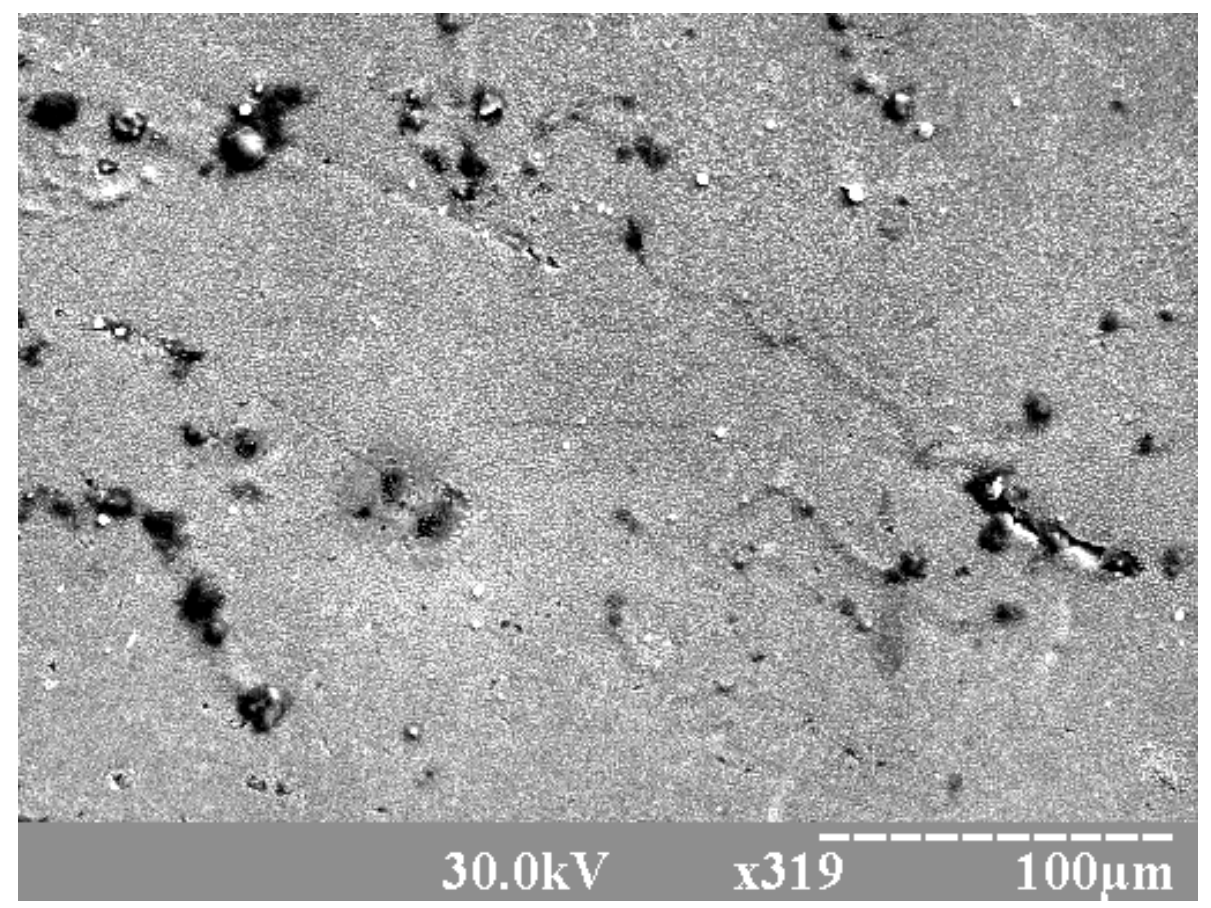

Fig.9. Microstructure of the DTF using a mixture of $\mathrm{C}_{2} \mathrm{H}_{2} / \mathrm{H}_{2}$ with a ratio of $1 / 2$ at $13.5 \mathrm{kV}$ charging voltage, $100 \mathrm{~m}$ Torr pressure and 100 plasma pulses.

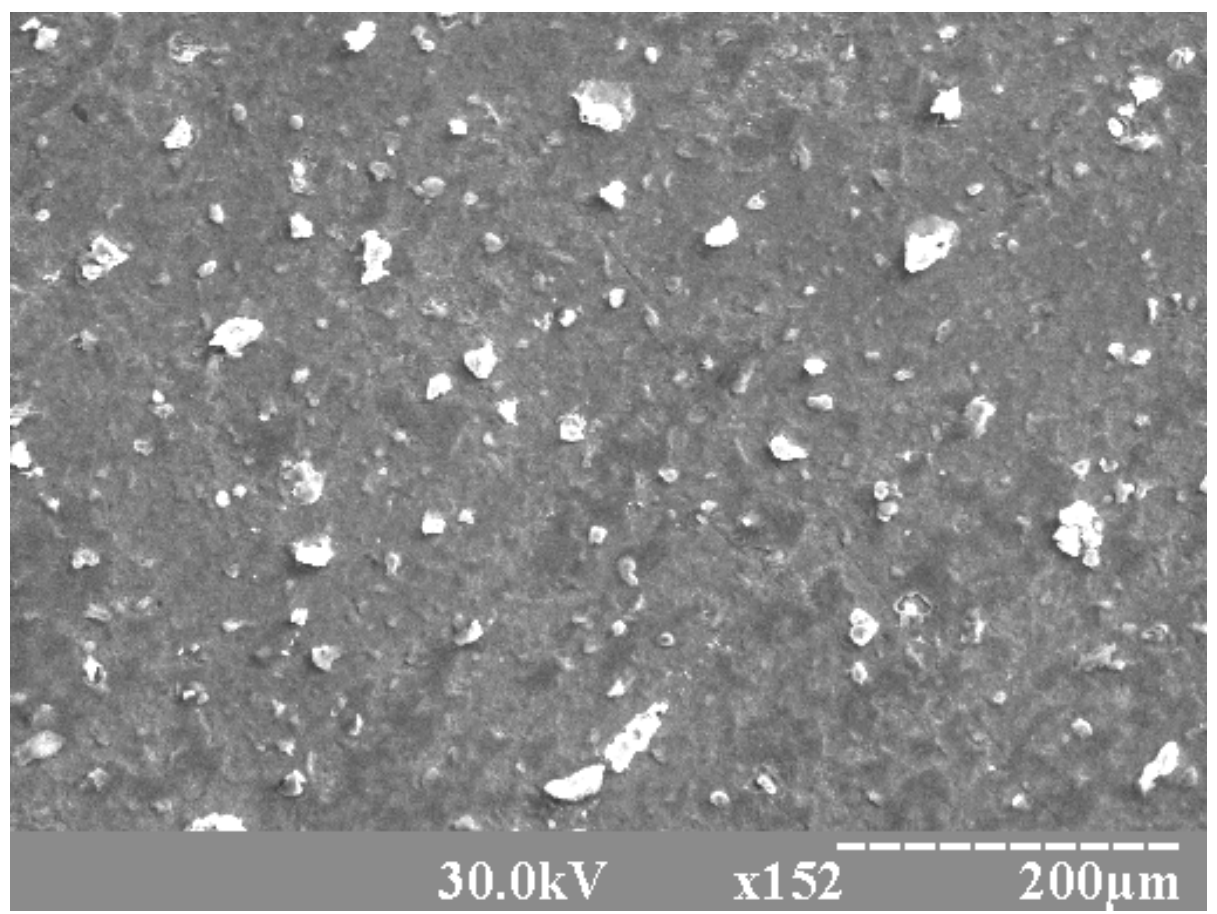

Fig.10. Microstructure of the DTF using a mixture of $\mathrm{C}_{2} \mathrm{H}_{2} / \mathrm{H}_{2}$ with a ratio of $1 / 2$ at $13.5 \mathrm{kV}$ charging voltage, $100 \mathrm{mTorr}$ pressure and 200 plasma pulses. 


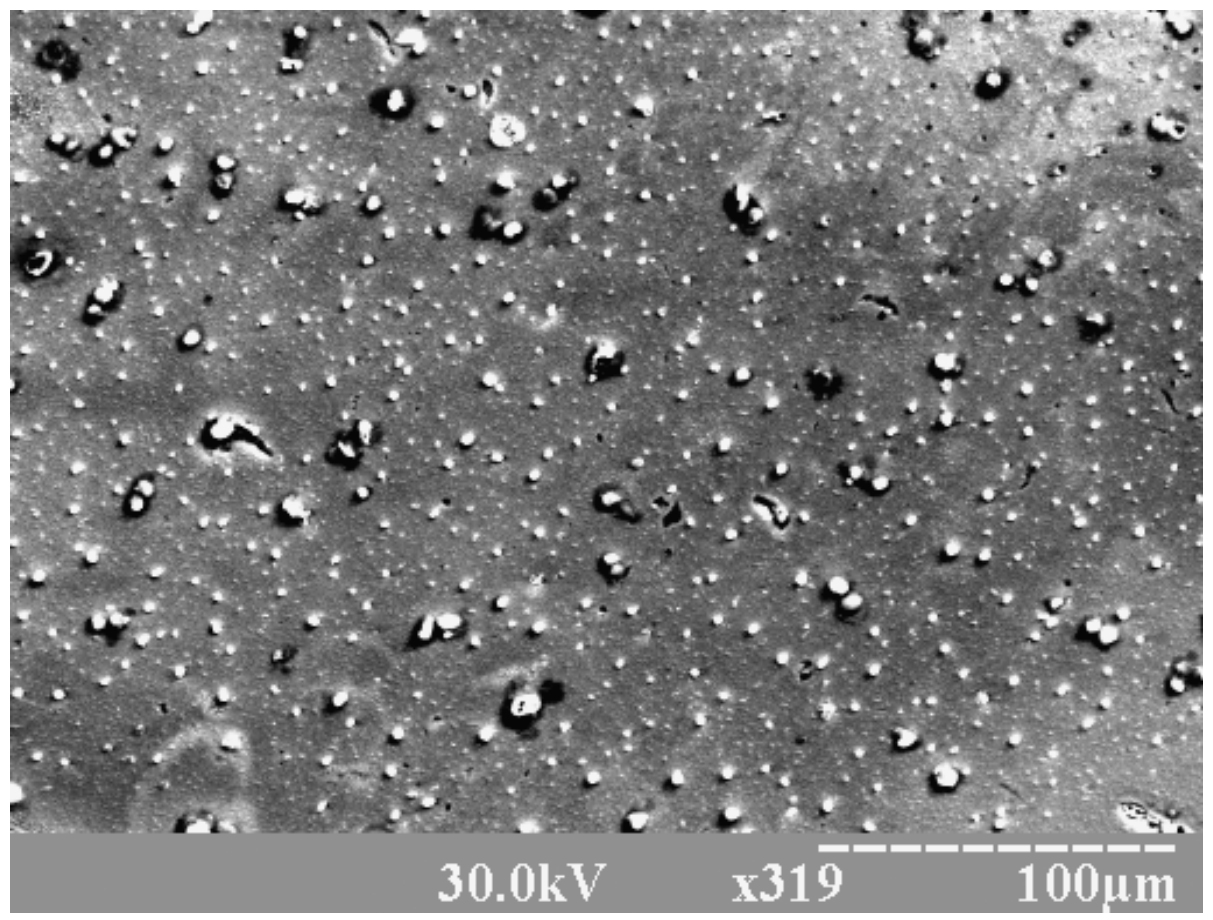

(a)

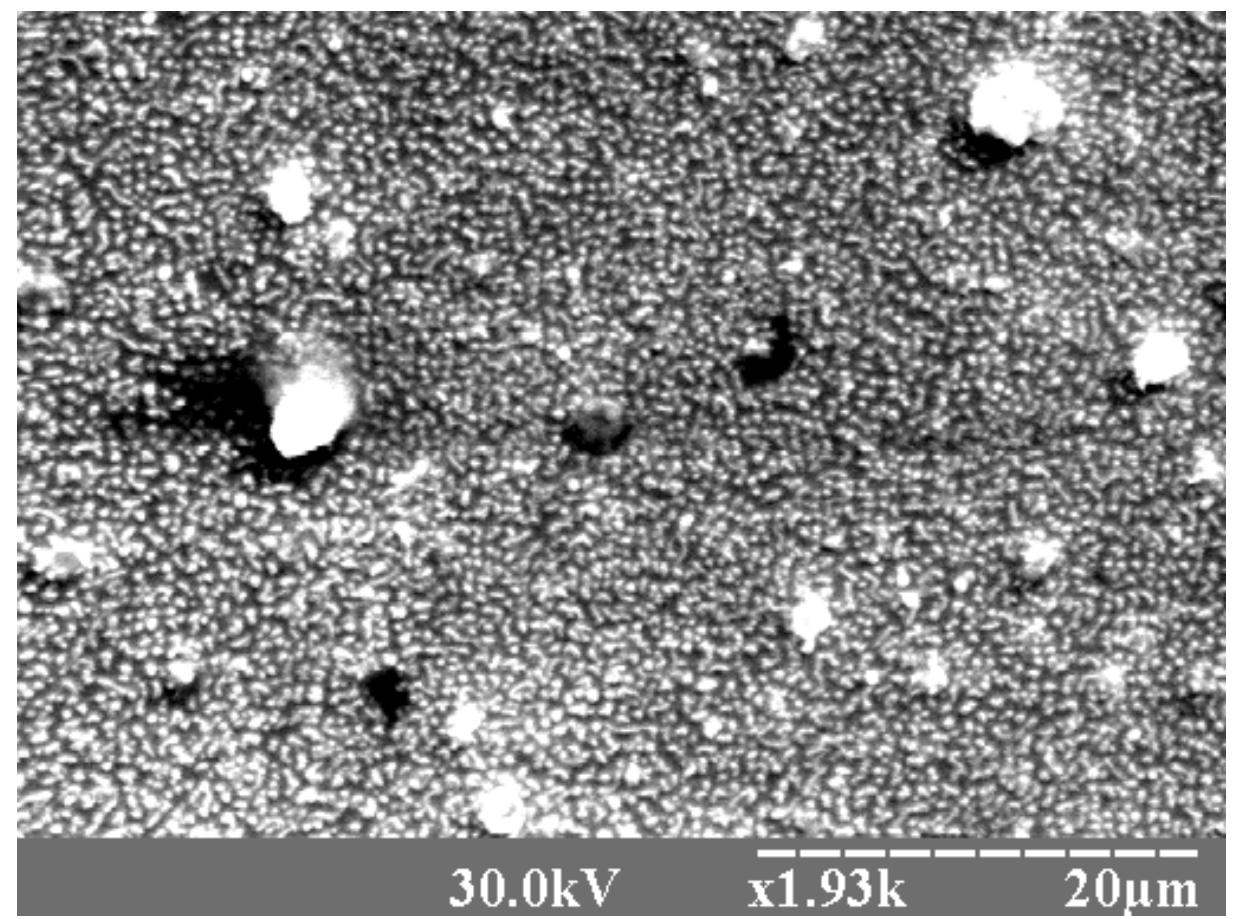

(b)

Fig.11. Microstructure of the DTF using a mixture of $\mathrm{C}_{2} \mathrm{H}_{2} / \mathrm{H}_{2}$ with a ratio of $1 / 5$ at $13.5 \mathrm{kV}$ charging voltage, $100 \mathrm{mTorr}$ pressure and 100 plasma pulses (a) Magnification 319 times. (b) Magnification 1930 times. 


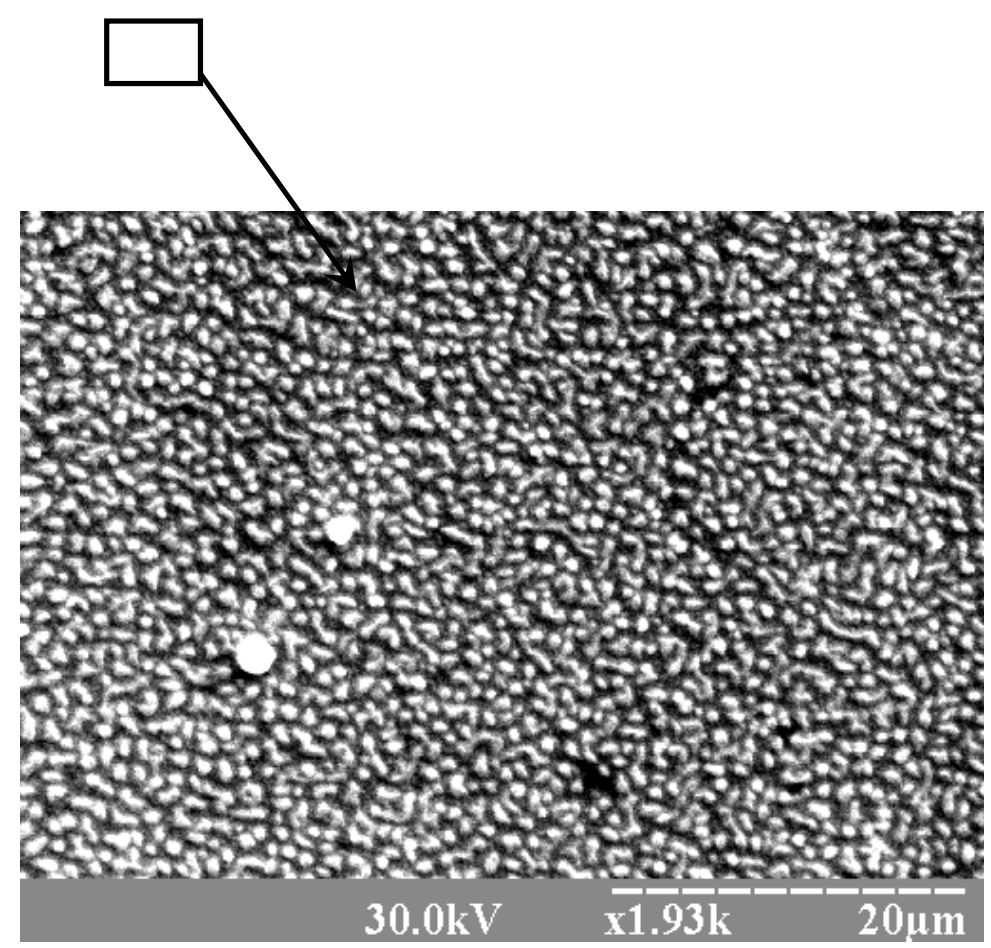

Fig.12. Microstructure of the DTF using a mixture of $\mathrm{C}_{2} \mathrm{H}_{2} / \mathrm{H}_{2}$ with a ratio of $1 / 5$ at $13.5 \mathrm{kV}$ charging voltage, 100 mTorr pressure and 200 plasma pulses 